\title{
Short communication: Variations in major mineral contents of Mediterranean buffalo milk and application of Fourier- transform infrared spectroscopy for their prediction
}

\author{
G. Stocco, ${ }^{*}$ C. Cipolat-Gotet, ${ }^{*}$ V. Bonfatti, $\dagger$ S. Schiavon, ${ }^{*}$ G. Bittante,${ }^{*}$ and A. Cecchinato*1 \\ *Department of Agronomy, Food, Natural Resources, Animals and Environment (DAFNAE), and \\ †Department of Comparative Biomedicine and Food Science (BCA), University of Padova, viale dell'Università 16 - 35020 Legnaro (PD), Italy
}

\begin{abstract}
The aims of this study were (1) to assess variability in the major mineral components of buffalo milk, (2) to estimate the effect of certain environmental sources of variation on the major minerals during lactation, and (3) to investigate the possibility of using Fouriertransform infrared (FTIR) spectroscopy as an indirect, noninvasive tool for routine prediction of the mineral content of buffalo milk. A total of 173 buffaloes reared in 5 herds were sampled once during the morning milking. Milk samples were analyzed for $\mathrm{Ca}, \mathrm{P}, \mathrm{K}$, and $\mathrm{Mg}$ contents within $3 \mathrm{~h}$ of sample collection using inductively coupled plasma optical emission spectrometry. A Milkoscan FT2 (Foss, Hillerød, Denmark) was used to acquire milk spectra over the spectral range from 5,000 to 900 wavenumber $/ \mathrm{cm}$. Prediction models were built using a partial least square approach, and crossvalidation was used to assess the prediction accuracy of FTIR. Prediction models were validated using a 4-fold random cross-validation, thus dividing the calibrationtest set in 4 folds, using one of them to check the results (prediction models) and the remaining 3 to develop the calibration models. Buffalo milk minerals averaged 162, 117,86 , and $14.4 \mathrm{mg} / \mathrm{dL}$ of milk for $\mathrm{Ca}, \mathrm{P}, \mathrm{K}$, and $\mathrm{Mg}$, respectively. Herd and days in milk were the most important sources of variation in the traits investigated. Parity slightly affected only Ca content. Coefficients of determination of cross-validation between the FTIRpredicted and the measured values were $0.71,0.70$, and 0.72 for $\mathrm{Ca}, \mathrm{Mg}$, and $\mathrm{P}$, respectively, whereas prediction accuracy was lower for $\mathrm{K}(0.55)$. Our findings reveal FTIR to be an unsuitable tool when milk mineral content needs to be predicted with high accuracy. Predictions may play a role as indicator traits in selective
\end{abstract}

Received April 11, 2016.

Accepted July 21, 2016.

${ }^{1}$ Corresponding author: alessio.cecchinato@unipd.it breeding (if the additive genetic correlation between FTIR predictions and measures of milk minerals is high enough) or in monitoring the milk of buffalo populations for dairy industry purposes.

Key words: buffalo milk, mineral content, Fouriertransform infrared spectroscopy

\section{Short Communication}

Buffalo (Bubalus bubalis) milk production is customary in many parts of the world, representing about $13 \%$ of worldwide global milk production, in second place after cow milk (FAOSTAT, 2014). Minerals are fundamental for human health, as they are required for many physiological functions such as tissue growth, blood clotting, muscle contraction, and nerve function, but they also play an important role in milk coagulation as they influence casein micelle structure and aggregation, rennet coagulation time, curd structure, and, ultimately, cheese yield (Lucey and Fox, 1993; Ariota et al., 2007). However, the concentrations of many minerals are altered as a result of mastitis (Ahmad et al., 2007; Eshratkhah et al., 2012). The mineral content of milk, as well as lactose, is subject to little variation during lactation and could be used as an indicator of infection of the mammary gland (El Zubeir et al., 2005). Therefore, determination of the milk mineral profile could be a means of evaluating the nutritional and technological quality of milk and as a tool for early diagnosis of subclinical mastitis (Managuli et al., 2014).The most common method for determining mineral content in milk for research purposes is inductively coupled plasma atomic emission spectrometry, although this method is too expensive and too time-consuming for routine analysis of milk samples on a wide scale. The current tool used to measure the major milk components during regular milk recording is Fourier-transform infrared (FTIR) spectroscopy; regarding the milk mineral profile, however, very little information exists in the literature regarding the use of FTIR spectroscopy, and most relates to bovine milk (Soyeurt et al., 2009). Re- 
cently, Bonfatti et al. (2015) investigated the ability of FTIR spectroscopy to predict the protein composition of buffalo milk, but so far no studies have investigated the possibility of predicting major mineral contents. The aims of our study were (1) to assess variability in the major mineral components of buffalo milk, (2) to estimate the effect of certain environmental sources of variation on the major minerals during lactation, and (3) to investigate the possibility of using FTIR spectroscopy for indirect prediction of the mineral content of individual buffalo milk samples.

A total of 173 Mediterranean buffaloes from 5 herds located in northern Italy were sampled once from January to May 2013. The number of animals sampled from each herd were 28, 29, 45, 39, and 32. Buffaloes were selected from each herd to represent the entire lactation and different parity order. Details of the sample procedure have been reported in Cipolat-Gotet et al. (2015). Milk samples were analyzed after dilution 1:100 (wt/wt) with ultrapure water. Inductively coupled plasma optical emission spectrometry (Ciros Vision EOP, Spectro Analytical Instruments GmbH, Kleve, Germany) was the reference method for determining $\mathrm{Ca}$ at $315.887 \mathrm{~nm}, \mathrm{P}$ at $177.495 \mathrm{~nm}, \mathrm{~K}$ at $766.491 \mathrm{~nm}$, and $\mathrm{Mg}$ at $280.270 \mathrm{~nm}$. Instrument operating parameters were optimized for acid solution, and calibration standards were matched with Suprapur nitric acid 5\% (Merck, Darmstadt, Germany). The elements to be determined were added from single element solutions (Inorganic Ventures, Christiansburg, VA). The concentration range of the calibration solutions was between 0 and $100 \mathrm{mg} / \mathrm{L}$ for each element. The accuracy and precision of this method were investigated by analyzing the certified reference material BCR - 063R "Skim milk powder" (Institute for Reference Materials and Measurements, Geel, Belgium). A MilkoScan FT2 (Foss, Hillerød, Denmark) was used to collect buffalo milk spectra over the spectral range from 5,000 to 900 wavenumber $/ \mathrm{cm}$. The transmittance spectra were converted in absorbance (A) spectra using the transformation A $=\log (1 / \mathrm{T})$, where $\mathrm{T}$ is the transmittance. Two spectral acquisitions were carried out for each sample and the results were averaged before data analysis.

Sources of variation in the minerals $(\mathrm{Ca}, \mathrm{P}, \mathrm{K}$, and $\mathrm{Mg}$ ) were investigated using the SAS GLM procedure (SAS Inst. Inc., Cary, NC) according to the following linear model:

$$
y_{i j k l}=\mu+\operatorname{DIM}_{i}+\text { Parity }_{j}+\text { Herd }- \text { Date }_{k}+e_{i j k l},
$$

where $y_{i j k l}$ is the observed trait (milk concentrations of $\mathrm{Ca}, \mathrm{P}, \mathrm{K}$, or $\mathrm{Mg}$ ); $\mu$ is the overall mean of the model;
$\mathrm{DIM}_{i}$ is the fixed effect of the $i$ th class of DIM $[i=1$ to 6: class $1,<30 \mathrm{~d}(\mathrm{n}=31)$; class $2,30-60 \mathrm{~d}(\mathrm{n}=24)$; class $3,61-120 \mathrm{~d}(\mathrm{n}=28)$; class $4,121-180 \mathrm{~d}(\mathrm{n}=27)$; class 5, 181-240 d ( $\mathrm{n}=37)$; class $6,>240 \mathrm{~d}(\mathrm{n}=26)$ ]; Parity $_{j}$ is the fixed effect of the $j$ th parity of the buffalo $(j=1$ to 4 or more; with number of buffaloes equal to $43,41,34$, and 55 for first, second, third, and fourth or more parity order, respectively); Herd - Date $_{k}$ is the fixed effect of the $k$ th herd-date of sampling ( $k=1$ to 5 ); and $e_{i j k l}$ is the random residual. Residuals were assumed to be independently and normally distributed with a mean equal to zero and variances of $\sigma_{e}^{2}$. Polynomial contrasts $(P<0.05)$ were estimated between least squares means of traits for DIM effect: first order-second order comparisons measured linear and quadratic relationships, respectively.

The FTIR calibration models were built using partial least-square regression procedures implemented in the WinISI II software (Infrasoft International LLC, State College, PA). Prediction models were validated using a 4-fold random cross-validation, thus dividing the calibration-test set in 4 folds, using one of them to check the results (prediction models) and the remaining 3 to develop the calibration models. The process was repeated until all folds had been used for validation once according to Naes et al. (2002). The FTIR spectra were analyzed across the whole interval (from 5,000 to 900 wavenumber $/ \mathrm{cm}$ ) and without the 2 portions known to be characterized by very high phenotypic variability (Bittante and Cecchinato, 2013); that is, the transition region between the short-wave to mid-wave infrared $\left(3,669-3,052 \mathrm{~cm}^{-1}\right)$ and the mid-wavelength infrared region from 1,698 to 1,586 wavenumber $/ \mathrm{cm}$. Several mathematical treatments of raw spectra were compared before regression analysis. Samples exhibiting a large spectral distance (i.e., a global Mahalanobis distance $>3$ ) from the population centroid and samples where the difference between the reference and the predicted values was much larger than the standard error of cross-validation were considered outliers and discarded from the calibration analysis.

Descriptive statistics of the major mineral contents of buffalo milk analyzed using inductively coupled plasma optical emission spectrometry instrument in the present study are summarized in Table 1, along with the most representative reference values reported in the literature, which are characterized by a very large variability. In our study, the Ca content averaged $162 \mathrm{mg} /$ $\mathrm{dL}$ of milk, similar to that reported in the "National nutrient database for standard reference" of the USDA (Agricultural Research Service, 2016). A review carried out by the Food and Agriculture Organization (FAO; 
Table 1. Descriptive statistics of major mineral contents of buffalo milk measured using inductively coupled plasma optical emission spectrometry, and comparison with references for buffalo and bovine milk

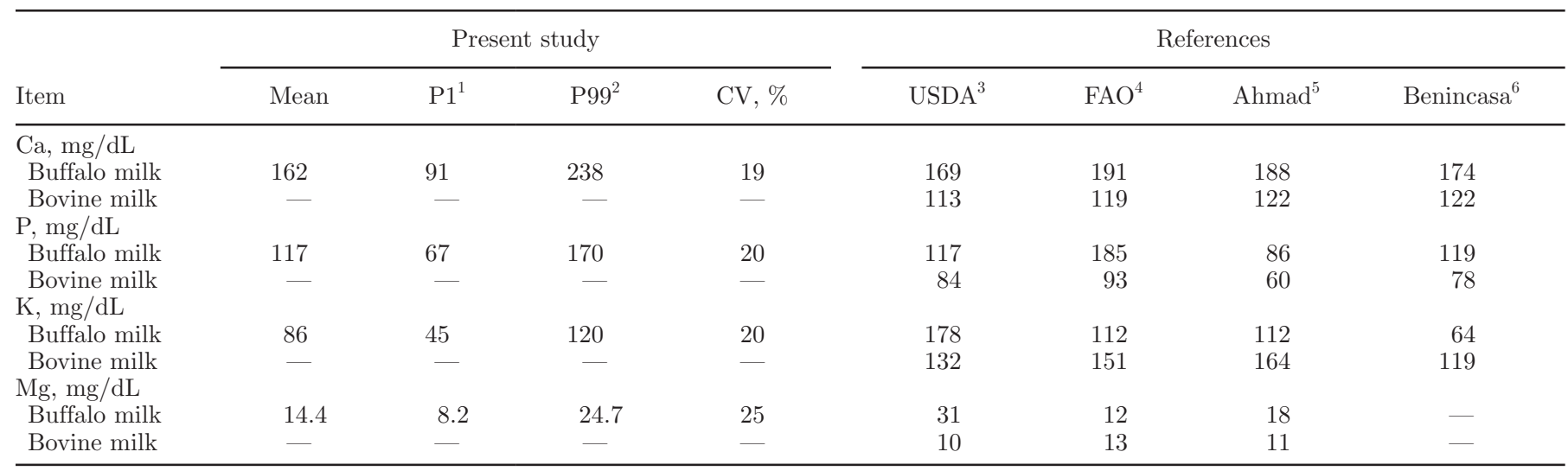

${ }^{1} \mathrm{P} 1=1$ st percentile.

${ }^{2} \mathrm{P} 99=99$ th percentile.

${ }^{3}$ According to the USDA "National nutrient database for standard reference," Agricultural Research Service (2016).

${ }^{4}$ According to a Food and Agriculture Organization of the United Nations review by Medhammar et al. (2012).

${ }^{5}$ According to a direct comparison between buffalo and cow milk by Ahmad et al. (2008).

${ }^{6}$ According to a direct comparison between buffalo and cow milk by Benincasa et al. (2008).

Medhammar et al., 2012) reported a higher average Ca content of buffalo milk, although the range of variation was very large (147 to $220 \mathrm{mg} / \mathrm{dL}$ ). Intermediate results were obtained by Ahmad et al. (2008) and Benincasa et al. (2008) in 2 direct comparisons of samples of buffalo and cow milk. According to these 4 sources of information, the Ca content is greater in buffalo milk than in cow milk by $50,61,54$, and $43 \%$, respectively.

In the present study, $\mathrm{P}$ content averaged $117 \mathrm{mg} / \mathrm{dL}$ of milk, almost identical to the average values reported

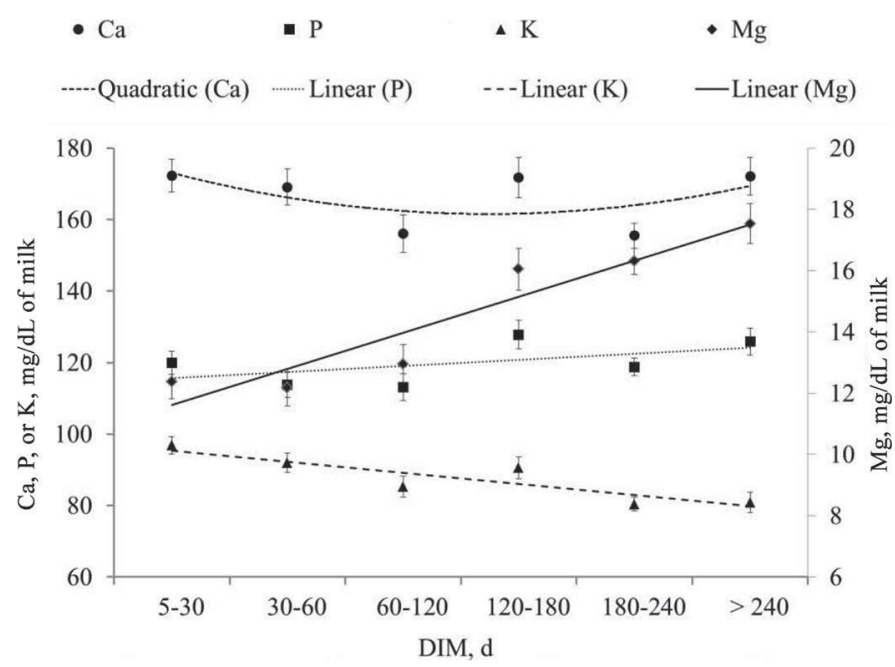

Figure 1. Least squares means and response curve of Ca, P, K, and $\mathrm{Mg}$ contents ( $\mathrm{mg} / \mathrm{dL}$ of milk) across class of DIM. The secondary vertical axis on the right side refers to $\mathrm{Mg}$ content. by the USDA (Agricultural Research Service, 2016) and by Benincasa et al. (2008) in their comparative study, whereas average $\mathrm{P}$ content reported by Medhammar et al. (2012) was much higher (with a range of variation larger than for Ca: 102 to $293 \mathrm{mg} / \mathrm{dL}$ ) and that reported by Ahmad et al. (2008) was much lower. These 4 sources of information also found a considerably higher $\mathrm{P}$ content in buffalo milk than in cow milk: 39,53 , 99 , and $43 \%$, respectively. It worth noting that another study on Mediterranean buffaloes reared in Italy found an intermediate $\mathrm{P}$ content $(145 \mathrm{mg} / \mathrm{dL}$; Ariota et al., 2007).

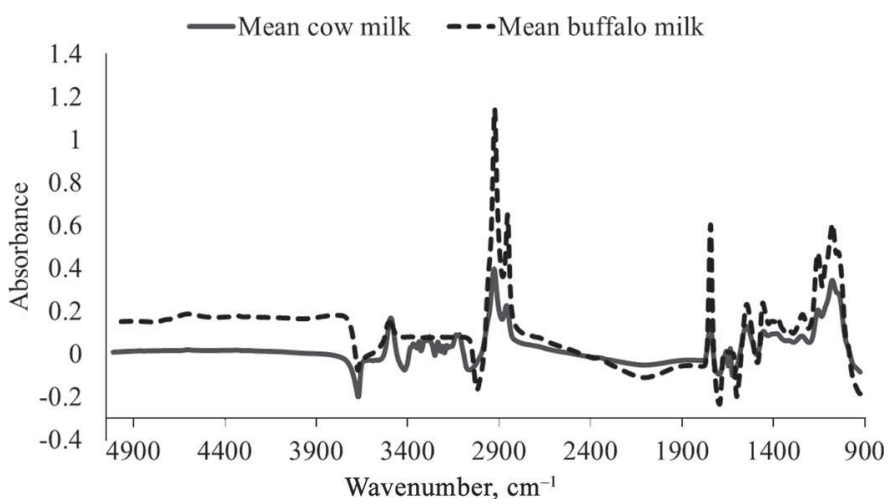

Figure 2. Average Fourier-transformed infrared absorbance spectra of buffalo and cow milk samples; solid line represents the average cow milk, whereas the dashed line represents the average of buffalo milk. 
Table 2. Results from ANOVA ( $F$-values and significance) for major mineral contents, measured using inductively coupled plasma optical emission spectrometry, in Mediterranean buffalo milk

\begin{tabular}{|c|c|c|c|c|c|c|c|}
\hline Item & Herd/date & DIM & \multicolumn{2}{|c|}{ Contrast } & Parity & $\mathrm{R}^{2}, \%$ & $\mathrm{RMSE}^{1}$ \\
\hline $\mathrm{P}, \mathrm{mg} / \mathrm{dL}$ & $25.5^{* * *}$ & $2.5^{*}$ & $4.1^{*}$ & 1.0 & 1.8 & 53 & 16.4 \\
\hline $\mathrm{K}, \mathrm{mg} / \mathrm{dL}$ & $17.4^{* * *}$ & $7.3^{* * *}$ & $22.9^{* * *}$ & 0.2 & 1.9 & 48 & 12.7 \\
\hline $\mathrm{Mg}, \mathrm{mg} / \mathrm{dL}$ & $4.8^{* * *}$ & $14.3^{* * *}$ & $65.0^{* * *}$ & 0.8 & 1.6 & 45 & 2.83 \\
\hline
\end{tabular}

${ }^{1} \mathrm{RMSE}=$ root mean square error.

${ }^{*} P<0.05 ; * * P<0.01 ; * * * P<0.001$.

The $\mathrm{K}$ content of buffalo milk was $86 \mathrm{mg} / \mathrm{dL}$ in the present study, whereas the other sources of information varied greatly in their findings. The USDA (Agricultural Research Service, 2016) reported the average K content to be double that found in the present study (Table 1) and $35 \%$ greater than in cow milk, whereas both the FAO (Medhammar et al., 2012) survey and the comparative study (Benincasa et al., 2008) reported intermediate values of 26 and $32 \%$ less than cow milk, respectively. The value reported by Benincasa et al. (2008) is lower than that in the present study, and $46 \%$ lower than in bovine milk (Table 1).

Lastly, the various sources of information found large variability also in the $\mathrm{Mg}$ content of buffalo milk (14.4 $\mathrm{mg} / \mathrm{dL}$ in the present study). The USDA (Agricultural Research Service, 2016) found it to be more than double that in the present study and $210 \%$ more than in cow milk, whereas in the FAO survey (Medhammar et al., 2012 ) it was $17 \%$ lower than in the present study and slightly lower than cow milk. In the direct comparison made by Ahmad et al. (2008), Mg was $25 \%$ higher than in the present study and $64 \%$ higher than in cow milk. Although the mineral composition of milk is thought to be relatively constant (Gaucheron, 2005), our study revealed substantial variation in the concentrations of $\mathrm{Ca}, \mathrm{P}, \mathrm{K}$, and $\mathrm{Mg}$ in buffalo milk, with the coefficient of variation ranging from 19 to $25 \%$.

Results from an ANOVA ( $F$-values and significance) on the major mineral contents of buffalo milk are summarized in Table 2. In general, the herd/date effect was the most important source of variation. An important factor differentiating the mineral contents of milk from different buffalo herds is probably feeding, as shown by studies on mineral supplementation (Shahzad et al., 2007; Begum et al., 2010; Neglia et al., 2014). Days in milk significantly affected all the traits examined, in particular $\mathrm{K}$ and $\mathrm{Mg}$ concentrations $(P<0.001)$. The $\mathrm{Mg}$ content tended to increase linearly from about 11 $\mathrm{mg} / \mathrm{dL}$ at the beginning of lactation to almost $18 \mathrm{mg} /$ $\mathrm{dL}$ at the end, whereas $\mathrm{K}$ tended to decrease from 96 to $80 \mathrm{mg} / \mathrm{dL}$ (Figure 1). The $\mathrm{P}$ content of buffalo milk tended to increase slowly during lactation, whereas the Ca content tended to decrease in the first part of lactation and to increase thereafter (Figure 1). Parity only affected the concentration of Ca (Table 2), which tended to decrease in adult buffaloes (data not shown).

Table 3. Fitting statistics of predictions models for Ca, P, K, and Mg contents in Mediterranean buffalo milk

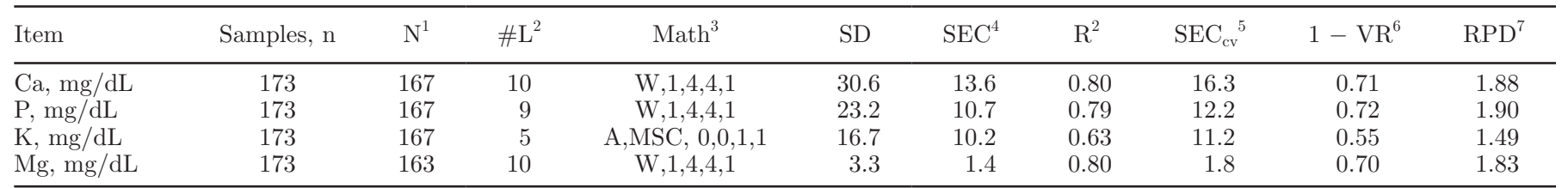

${ }^{1} \mathrm{~N}=$ number of samples used in the calibration after removing outliers.

${ }^{2} \# \mathrm{~L}=$ number of partial least square latent components.

${ }^{3} \mathrm{Math}=$ mathematical treatment of the spectral data, where the letters indicate the spectral range used for calibration. A $=$ all the spectrum $5,011-930 \mathrm{~cm}^{-1} ; \mathrm{W}=$ spectra segments used 5,011-3,673 $\mathrm{cm}^{-1}, 3,048-1,701 \mathrm{~cm}^{-1}$, and 1,582-930 $\mathrm{cm}^{-1}$; MSC = multiplicative scatter correction. The first number is the order of the derivative, the second number is the segment length in data points over which the derivative was taken, and the third and fourth numbers are the segment length for first and second smoothing, respectively.

${ }^{4} \mathrm{SEC}=$ standard error of calibration.

${ }^{5} \mathrm{SEC}_{\mathrm{cv}}=$ standard error of cross-validation.

${ }^{6} 1-\mathrm{VR}=$ prediction accuracy (coefficient of determination of cross-validation).

${ }^{7} \mathrm{RPD}=$ ratio performance deviation 
Figure 2 shows comparison of the different absorbance spectra of average cow and buffalo milk samples. The differences are mainly due to the protein and fat areas. According to Etzion et al. (2004), absorbance of protein bonds is in the range between 1,500 and 1,700 $\mathrm{cm}^{-1}$, known as the amide I and amide II bands, and between 1,060 and $1,100 \mathrm{~cm}^{-1}$, which is associated with phosphate groups covalently bound to caseins. Lipids are recognized in the region 3,000 to $2,800 \mathrm{~cm}^{-1}$, which accounts for the observed peaks at 2,928 and 2,855 $\mathrm{cm}^{-1}$ (Lefèvre and Subirade, 2000), and between 1,736 and $1,805 \mathrm{~cm}^{-1}$, where $1,745 \mathrm{~cm}^{-1}$ is the frequency correlating with the fatty acid carbonyl group (Coates, 2000). The peaks in the region between 640 and 1,500 $\mathrm{cm}^{-1}$ are due to $\mathrm{C}-\mathrm{H}$ bending $\left(1,493 \mathrm{~cm}^{-1}\right)$ and $\mathrm{C}-\mathrm{O}$ stretching $\left(1,157,1,080 \mathrm{~cm}^{-1}\right)$.

Fitting statistics for prediction models for major mineral contents in Mediterranean buffalo milk are summarized in Table 3. Coefficients of determination in cross-validation were 0.70 to 0.72 for $\mathrm{Ca}, \mathrm{P}$, and $\mathrm{Mg}$, but lower (0.55) for K (Figure 3). The corresponding values of ratio performance deviation (RPD) were
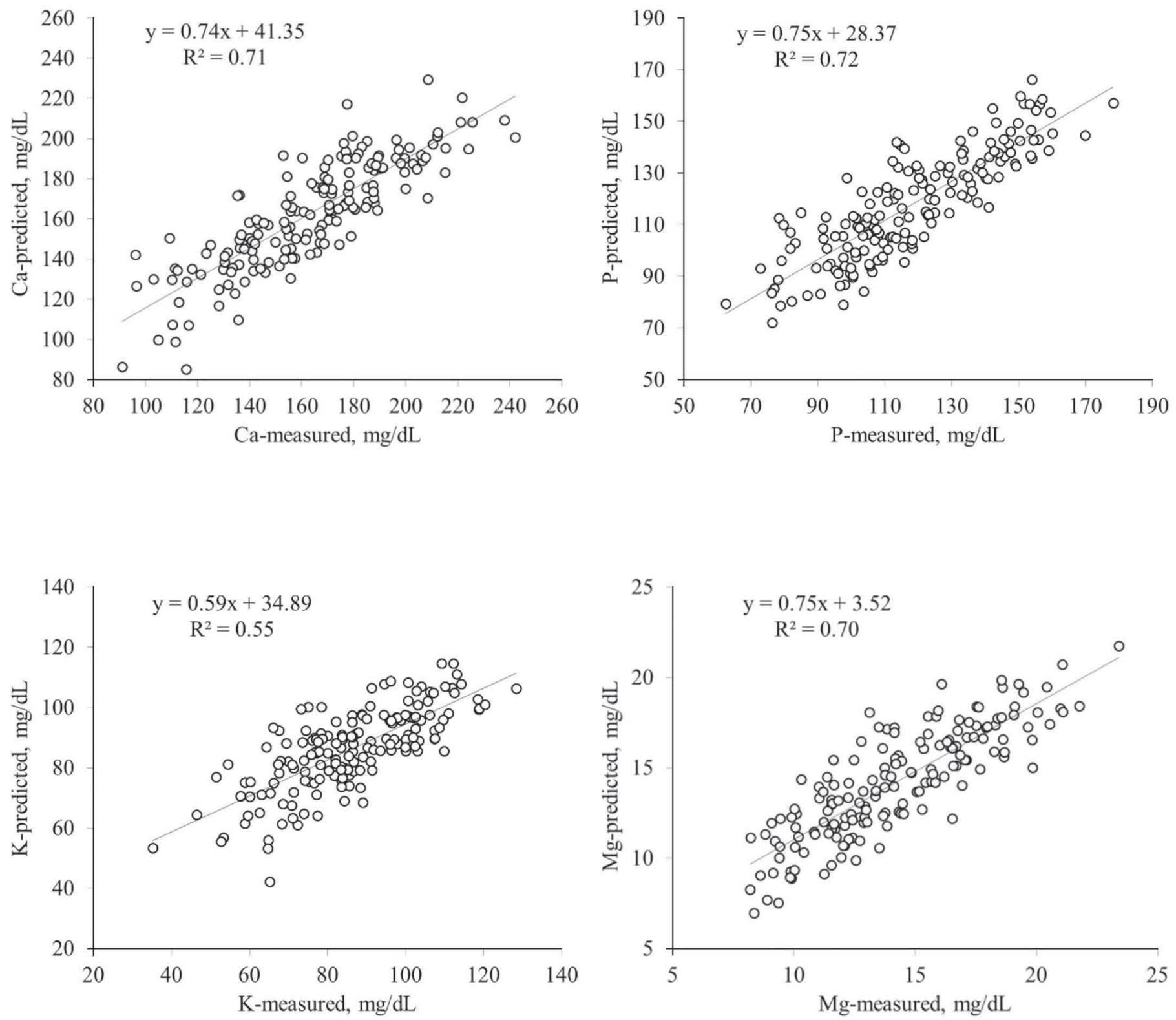

Figure 3. Scatter plots of predicted versus measured values of $\mathrm{Ca}, \mathrm{P}, \mathrm{K}$, and $\mathrm{Mg}$ contents (mg/dL of milk) in buffalo milk. 
$1.88,1.90,1.49$, and 1.83 for $\mathrm{Ca}, \mathrm{P}, \mathrm{K}$, and $\mathrm{Mg}$, respectively. Manley (2014) reported that the RPD attempts to scale the error in prediction with the standard deviation of the property. The RPD values greater than 3 are useful for screening, values greater than 5 can be used for quality control, and values greater than 8 for any application. To our knowledge, no previous studies have been done on the prediction of mineral contents in buffalo milk using FTIR spectroscopy, although some have been done on bovine species. Soyeurt et al. (2009) investigated the potential of FTIR to predict the Ca, P, $\mathrm{Mg}, \mathrm{Na}$, and $\mathrm{K}$ contents of cow milk using the inductively coupled plasma atomic emission spectrometry as a reference method. Their results showed that FTIR has a good ability to predict bovine $\mathrm{Ca}$ and $\mathrm{P}$ (coefficient of determination of cross-validation of 0.87 and 0.85 , respectively), has reasonable levels of accuracy for $\mathrm{Mg}$ and $\mathrm{Na}$ (coefficient of determination of crossvalidation of 0.65 ), but yields unsatisfactory results for $\mathrm{K}$, as in the present study on buffalo milk. The coefficient of determination of cross-validation was identical to that obtained in the present study for $\mathrm{P}(0.72)$, but lower for $\mathrm{Ca}$ (0.56 for cows vs. 0.71 for buffaloes). The higher predictive ability obtained by Soyeurt et al. (2009) could be attributed to a different sample processing method, as they selected a subsample (100 out of 1,543 samples) from their spectral variability using a principal components approach, thereby maximizing the variability of the calibration set. The FTIR calibrations obtained for buffalo milk, as for bovine milk, may be considered unsatisfactory if the objective is to substitute a reference method for accurate and precise evaluation of the mineral content of a milk sample. Nevertheless, considering that FTIR predictions are rapid and cheap, that multiple predictions can be easily obtained for each animal across lactation, and that such calibrations allow for discrimination between high and low values of the traits, several applications are possible. Predictions may have potential, at least in the case of $\mathrm{Ca}, \mathrm{P}$, and $\mathrm{Mg}$, for early identification of udder problems in buffaloes, for monitoring the quality of milk at the farm level, and for genetic selection programs at the population level (provided the additive genetic correlation between FTIR predictions and measures of milk minerals is high enough). Finally, in-depth study of the relationship between major mineral components and mastitis as well as milk coagulation properties and cheese yield in buffalo milk could be of particular interest for future research.

\section{ACKNOWLEDGMENTS}

The authors thank the technical staff at the breeder associations of the Provinces Treviso and Padua and the Region of Friuli-Venezia Giulia for providing milkrecording data and assistance in data collection. We also thank the managers of the 5 dairy farms sampled for their collaboration. This research was supported by the University of Padua (Ricerca Scientifica fondi quota EX 60\% - 60A08-7943/14).

\section{REFERENCES}

Agricultural Research Service. 2016. National nutrient database for standard reference, release 27. United States Department of Agriculture, Washington, DC. Accessed Aug. 24, 2016. https://ndb. nal.usda.gov/ndb/search.

Ahmad, T., M. Q. Bilal, S. Uallah, Z. Rahman, and G. Muhammad. 2007. Impact of mastitis severity on mineral contents of Buffalo milk. Pakistan J. Agric. Sci. 44(Suppl.1):176-178.

Ahmad, S., I. Gaucher, F. Rousseau, E. Beaucher, M. Piot, J. F. Grongnet, and F. Gaucheron. 2008. Effects of acidification on physico-chemical characteristics of buffalo milk: A comparison with cow's milk. Food Chem. 106:11-17.

Ariota, B., G. Campanile, A. Potena, R. Napolano, B. Gasparrini, G. L. Neglia, and R. Di Palo. 2007. Ca and P in buffalo milk: Curd yield and milk clotting parameters. Ital. J. Anim. Sci. 6(Suppl.1):497-499.

Begum, I., A. Azim, S. Akhter, M. L. Anjum, and M. Afzal. 2010. Mineral dynamics of blood and milk in dairy buffaloes fed on calcium and phosphorus supplementation. Pak. Vet. J. 30(Suppl.2):105-109.

Benincasa, C., J. Lewis, G. Sindona, and A. Tagarelli. 2008. The use of multielement profiling to differentiate between cow and buffalo milk. Food Chem. 110:257-262.

Bittante, G., and A. Cecchinato. 2013. Genetic analysis of the Fouriertransform infrared spectra of bovine milk with emphasis on individual wavelengths related to specific chemical bonds. J. Dairy Sci. 96:5991-6006.

Bonfatti, V., A. Cecchinato, and P. Carnier. 2015. Short communication: Predictive ability of Fourier-transform mid-infrared spectroscopy to assess CSN genotypes and detailed protein composition of buffalo milk. J. Dairy Sci. 98:6583-6587.

Cipolat-Gotet, C., G. Bittante, and A. Cecchinato. 2015. Phenotypic analysis of cheese yields and nutrient recoveries in the curd of buffalo milk, as measured with individual model cheese-manufacturing process. J. Dairy Sci. 98:633-645.

Coates, J. 2000. Interpretation of infrared spectra, a practical approach. Pages 10815-10837 in Encyclopedia of Analytical Chemistry. R. A. Meyers, ed. John Wiley \& Sons, New York, NY.

El Zubeir, E. M. I., O. A. O. El Owni, and G. E. Mohamed. 2005. Correlation of minerals and enzymes in blood serum and milk of healthy and mastitic cows. Res. J. Agric. Biol. Sci. 1(Suppl.1):45-49.

Eshratkhah, B., R. Beheshti, and J. Shayegh. 2012. Variation of some minerals values in subclinical mastitic milk of Buffalo during different ages and lactation stages. Glob. Vet. 8(Suppl.4):333-337.

Etzion, Y., R. Linker, U. Cogan, and I. Shmulevich. 2004. Determination of protein concentration in raw milk by mid-infrared Fouriertransform infrared/attenuated total reflectance spectroscopy. J. Dairy Sci. 87:2779-2788.

FAOSTAT. 2014. Food and Agriculture Organization of the United Nations (FAO) statistical database. Accessed Aug. 24, 2016. http://faostat.fao.org/site/291/default.aspx.

Gaucheron, F. 2005. The minerals of milk. Reprod. Nutr. Dev. 45:473483.

Lefèvre, T., and M. Subirade. 2000. Interaction of $\beta$-lactoglobulin with phospholipids bilayers: A molecular level elucidation as revealed by infrared spectroscopy. Int. J. Biol. Macromol. 28:59-67.

Lucey, J. A., and P. F. Fox. 1993. Importance of calcium and phosphate in cheese manufacture: A review. J. Dairy Sci. 76(Suppl. 6):1714-1724. 
Managuli, S. S., A. S. Nagvekar, S. D. Ingole, and S. V. Barucha. 2014. Somatic cell count and major elements in milk during lactation in buffaloes. Indian J. Anim. Sci. 84:797-798.

Manley, M. 2014. Near-infrared spectroscopy and hyperspectral imaging: Non-destructive analysis of biological materials. Chem. Soc. Rev. 43:8200-8214

Medhammar, E., R. Wijesinha-Bettoni, B. Stadlmayr, E. Nilsson, U. R. Charrondiere, and B. Burlingame. 2012. Composition of milk from minor dairy animals and buffalo breeds: a biodiversity perspective. J. Sci. Food Agric. 92:445-474.

Naes, T., T. Isaksson, T. Fearn, and A. Davies. M. 2002. A UserFriendly Guide to Multivariate Calibration and Classification. NIR Publications, West Sussex, UK.
Neglia, G., A. Balestrieri, B. Gasparrini, M. I. Cutrignelli, G. Bifulco, A. Salzano, R. Cimmino, E. Varricchio, M. J. D'Occhio, and G. Campanile. 2014. Nitrogen and phosphorus utilisation and excretion in dairy buffalo intensive breeding. Ital. J. Anim. Sci. 13:3362.

Shahzad, M. A., M. Sarwar, and M. Mahr-un-Nisa. 2007. Effect of dietary cation anion difference on buffalo performance during summer. Ital. J. Anim. Sci. 6(S2):491-494.

Soyeurt, H., D. Bruwier, J.-M. Romnee, N. Gengler, C. Bertozzi, D. Veselko, and P. Dardenne. 2009. Potential estimation of major mineral contents in cow milk using mid-infrared spectrometry. J. Dairy Sci. 92:2444-2454 